\title{
Dynamic Systems Modeling in Educational System Design \& Policy
}

\author{
Jennifer Sterling Groff * \\ Learning Games Network, Center for Curriculum Redesign, and Sterling Education Design, USA \\ \{jennifer_groff@mail.harvard.edu\}
}

Received on 11 February 2013; revised on 13 February 2013; accepted on 19 April 2013; published on 15 July 2013

DOI: $10.7821 /$ naer.2.2.72-81

\begin{abstract}
Over the last several hundred years, local and national educational systems have evolved from relatively simple systems to incredibly complex, interdependent, policy-laden structures, to which many question their value, effectiveness, and direction they are headed. System Dynamics is a field of analysis used to guide policy and system design in numerous fields including business and urban planning. Applying this tool to educational policy analysis offers insights into the hidden dynamics of the current system, and can be an invaluable tool in designing future scenarios. We explore underlying dynamics of the current US educational system using System Dynamics modeling, and offer an analysis of this tool and its practical application in the US educational system through a case study on the US state of Rhode Island in the 2007-2008 school year.
\end{abstract}

KEYWORDS: POLICY, SYSTEM ANALYSIS, SYSTEMS DEVELOPMENT, EDUCATIONAL REFORM

\section{INTRODUCTION}

What type of educational system do we want? What does it look like? How can we get there?

Over the last hundred years, local and national educational systems have evolved from relatively simple systems to incredibly complex, interdependent, policy-laden structures, to which many question their value, effectiveness, and direction they are headed. These systems have evolved over time through growth and restructuring driven by systemic policies crafted over the years. When red flags occur in the system - such as student achievement scores, dropout rates, teacher attrition, etc.- they prompt officials to construct, or reconstruct, policies to improve the situation. However, shaping future policies and system design requires careful consideration system dynamics that is often neglected in policy development (Axelrod, 1976). In fact, it is often the case that the very policies crafted to improve the red flags end up making the situation worse (Sterman, 2001). Figure 1 is a real life example of such a scenario.

In education, we can find a similar example. The U.S. No Child Left Behind Act of 2001 was a federal law instituted to address several major "red flags" within the United States' educational system-particularly the lack of student achievement and rigorous learning signifying a quality education. Components of the act included increased accountability of schools based on student achievement on standardized tests in order to receive federal funding - with an ultimate goal of $100 \%$ of American students reaching at least "proficient" status on these tests by the year 2013/2014. However, since the law's enactment, several systemic effects have panned out: classroom instructional time in many schools has dramatically shifted towards teaching content of the standardized assessments at the occlusion of other subjects (McMurrer, 2008); test scores have appeared to be on the rise, however numerous states have since restructured their standardized tests that more test scores are able to be deemed proficient (Jennings \& Rentner, 2006); and some schools and districts are refusing to participate, citing that they would rather seek funding from other sources (Krone, 2008; Pascopella, 2004). Clearly, these were unintended effects the policymakers had not planned on.

John Sterman refers to such examples as policy resistancethe "tendency for interventions to be defeated by the response of the system to the intervention itself" (2001, p. 8). Our inclination to draft and institute such policies stems from two sources. One is our daily and constant interplay with simple systems, where we directly observe cause and effect occur in close proximity. For example, we see the front door is left open, so we walk over and close the door - the problem has been resolved. In this linear type of thinking, we get information about a problem, take action, and expect a result. However much of our world operates in a nest of complexity, where effects of our actions are not immediate or directly observable, and can have far-reaching affects in the dynamics of the system in which the initial problem is situated. This challenge is exacerbated for us by the fact that "truths learned from simple systems are often completely opposite from the behavior of more complex systems" (Forrester, 1997, p. 9).

\footnotetext{
*To whom correspondence should be addressed:

Learning Games Network

222 Third Street

Suite 0300

Cambridge, MA 02142
} 
Figure 1. Example of system dynamics analysis in policy design (Source: Forrester, 1969; Forrester, 1991).

\begin{abstract}
An Example of System Dynamics in Urban Policy / Planning
In 1968, Jay Forrester worked closely with former Boston mayor John Collins to look at the challenges of urban design, using system dynamics tools. One area in which they examined was low-cost housing - meaning housing constructed for the underemployed and not available to any other segment of the population. Working closely with city officials, they found that:

Economic distress in declining American cities in the 1960s generated symptoms of high unemployment and deteriorating housing. It appeared natural enough to combat such symptoms by government intervention to build low-cost housing. But the modeling study showed, as events have since confirmed, that such urban areas already have more low-cost housing than the economy of the city can sustain. Public policy to build more such housing merely occupies land that could instead have been used for job-creating businesses, while at the same time the housing attracts people who needed jobs. A low-cost housing program introduces a powerful double force for increasing unemployment, both by reducing employment while at the same time attracting people seeking work. Low-cost housing programs in inner cities become a social trap. The policy of building low-cost housing actually creates poor and unemployed people, rather than alleviating personal hardship. (Forrester, 1991, p. 19)
\end{abstract}

Ultimately, constructing low-cost housing was a powerful process for creating poverty, not alleviating it. This example demonstrates how the natural human tendency to attack symptoms of a problem; however, in the end this may be counterproductive and actually harmful to the system seeking corrections in the future. Rather, identifying the system cause of the problem and generating a high-leverage is the long-term solution to the problem.

The other root is from the human tendency towards analysisbreaking things down to examine each piece, which is where much of our conventional wisdom comes from and is generally how we are educated (Meadows, 1991). As a result of our daily interactions combined with our formal education, we all walk around with mental models of how the world works, which are abstractions based on this world experience. Our mental models and abstractions drive our behavior, from the very simple shutting of a door, to the attempts to create solutions to the world's most complex challenges. However, mental models have serious shortcomings. We are often unaware of assumptions about how things work because our mental models are incomplete- -limited, internally inconsistent, and unreliable" (Sterman, 2001, p. 10). Forrester explains,

the human mind is not adapted to understanding correctly the consequences implied by a mental model. A mental model may be correct in structure and assumptions but, even so, the human mind - either individually or as a group consensus - is apt to draw the wrong implications for the future (1971, p. 5).

How can we be so sure? Over the last 50 years the field of system dynamics has been leveraging the power of dynamic systems modeling and computer applications to demonstrate the complexity of our world and how understanding that complexity can help us to predict the behavior of complex systems and the appropriate policies we should craft for those systems.

\section{THE NEED FOR A NEW APPROACH: A HISTORY OF MIRED PROGRESS AND PERILS OF EDUCATION REFORM}

Since its appearance in the U.S. in the 1960s, education system reform has a long and varied history with limited success. During these decades we saw considerable investment of federal funds towards various programs designed to produce better learning outcomes. However, according to a comprehensive study conducted by the Rand Corporation, most of these programs - both large and small - came up short, explaining that many of these programs were adopted due to the incentives for the federal funds rather than in pursuit of deeply changing educational practice, with few programs being implemented properly in the first place and demonstrating little if any sustained growth (Berman \& McLaughlin, 1978). With this lack of growth and disconnect, and only isolated pockets of improved classroom instruction, the 1970 s showed to be a stagnant period in educational system change-ultimately propelling the 1983 release of $A$ Nation at Risk, spurring the accountability movement of the 1980s and the introduction of large-scale governmental regulation through mandated curricula and competency testing.

For many, the publication of $A$ Nation at Risk marks a turning point in the discourse and emphasis on education reform; however, the outcomes post-1983 generally mirrored the level of impact and challenges encountered before. The 1980s became a time of strategy towards decentralization, where schools had increased ownership of their decision-making, allowing more flexibility to meet the needs of the specific context of each school became the mode of emphasis. Yet with many of these efforts operating on emphasis and strict adherence to implementation guides, school were not left with the flexibility to adopt and adapt a program to meet their needs (Fullan, 1991). Michael Fullan, Professor Emeritus of the Ontario Institute for Studies in Education of the University of Toronto, arguably has the strongest track-record of effective strategies in large-scale reform concluded that "restructuring reforms that devolved decision making to schools may have altered governance procedures but did not affect the teaching-learning core of schools" (1995, p. 230). Countless case studies of districts attempting restructuring initiatives have demonstrated that the core goal of improving teaching-learning practices to increase student performance had not occurred. This sporadic progress left many education stakeholders and reformers spurring towards large-scale, comprehensive reform that dominated the 1990s.

In fact, Fullan has argued that the largest hindrance to reform is the presence of too many ad hoc, uncoordinated innovations and policies (1999). Whole School Reform Models emerged in response to this, where the entire school seeks to adopt a new model (examples include Success for All, Expeditionary Learning Schools, CO-NECT Schools). These models have shown varied success depending on their implementation. On a review of 16 initiatives, (Datnow \& Stringfield, 2000) found that whole-school reform models can have successful outcomes when strong district and state support is present. Unfortunately, in hindsight, many schools adopted a certain model without the consideration of how it will fit the school's goals, culture, teachers, or students, resulting in minimal positive outcomes and sustained improvement. This has ultimately pushed Fullan and others to believe the only effective method for systemically improving large school systems is to not pursue a top-down nor a bottom-up approach, but rather an approach that holistically 
works with all levels together-what Fullan calls the Tri-Level model that address the three critical levels of school systems: school \& community, district and state (Fullan, 1994; Fullan, 2001; Fullan, Rolheiser et al, 2001; Barber \& Fullan, 2005).

In reflecting on the journey of education reform, Fullan concludes: "as long as you have external models coming and going there will never be more than a small proportion of schools and districts involved, and any pockets of success will be short-lived (2001, p. 4);" therefore, "the primary goal is to alter the capacity of the school to engage in improvement" [and] second, "sustainable reform can only be achieved when working with whole systems" (2001, p. 5). Aligning the whole system is critical, because no matter what capacity and gains a school makes, if the outer policies undermine those initiatives, the school improvement cannot and will be sustained.

Fullan's whole-system approach shows promise, but it is clear to most education stakeholders that we are still far from having the optimal education systems we desire. What truly is happening in these reforms efforts that is inhibiting the change we seek? What hidden effects and dynamics are in place that actually produce the outcomes we see rather than those we desire?

\section{SYSTEM DYNAMICS AND EDUCATION POLICY}

Fullan's whole-system approach actually preludes an approach and mind-set employed by many other societal systems and structures known as System Dynamics modeling-a methodology that helps us better design and respond to the complex systems that make up our world.

In reality, all of our societal structures and complex systems and what Fullan began to observe and response to is the nature these systems, which are complex, interconnected structures that are filled with feedback loops where behaviors and actions in one part of the system impact (or are constrained) by other parts of the system. They are characterized by nonlinear, counterintuitive behavior, where not only is effect rarely proportional to cause, but often they are far apart in the system. In other words, effects or changes to one part of the system often play out much differently than intended because the change causes dynamic effects in the system as a whole. This complexity makes all systems inherently difficult to understand intuitively and therefore policy resistant - because our decisions often elicit unintended responses (Sterman, 2001). The education system is no different from other complex systems. There are many examples in current education policy where the outcomes are very different than what had been intended (Groff, 2009; Wheat, 2000). An example of this is provided in Box 2.

System Dynamics (SD), a methodology and larger field of study, was developed more than 50 years ago in an effort to cope with the complexity and difficulty in working with complex systems, and has subsequently been applied to numerous fields, including businesses, medicine, economic behavior and even environmental change (Forrester, 1998). In essence, this methodology helps us create models of the key dynamics in a given system, by offering tools to:

- map the feedback structure of a system in order to understand why a system is behaving the way it is;

— test and plan for policies before implementing them; and

- to increase the likelihood they produce the outcomes desired.
Unfortunately, these tools have rarely been used in education policy. Despite the fact that several notable researchers began introducing these tools to the education reform discourse over two decades ago, one can speculate that this lack of presence in education reform work is largely due to people's lack of familiarity with complex systems and systems thinking-as evidenced by the design of most of the reform work of the past 50 years. Though sparse, these rare examples are worth noting here.

Wheat has illustrated unforeseen dynamics of student achievement when Standards of Learning were introduced to an education system by generating an unintended side-effect that undermined rather than supported the standards (2000). Wheat created a model that showed a "70-percent achievement rate" on the assessments introduced to accompany the standards, which to many seemed quite reasonable; however, as this goal is achieved over time, it will induce an expected increase in expectations that is unsustainable, impacting student/teacher motivation and "thereby reducing learning productivity and causing learning rates to be lower than they otherwise would be" (2000, p. 7).

How can this happen? Unfortunately, most legislation is designed with linear, cause-effect thinking, and it is passed with little or no analysis of its system effects by either policymakers or advocates. Jay Forrester, the father of SD, explains that "governments pass laws after superficial experiments using a country as a laboratory...including no dynamic modeling of the long-term effects" (1998 p. 6). Herein lies the greatest potential in SD tools - testing new policies and system changes, rather than using the current education system as a test bed for policies generated with human cause-effect thinking. Once a model is built using SD tools, one can better plan for policies and changes to the system by forecasting their dynamics. Although the method can be time-consuming and challenging, it offers the best way to "gain experience with a system, because activity in the real system is infeasible, costly, or impossible" (Banathy, 1973; Garet, 1974). Forrester advocates for this type of 'designing the future'-"people try to cope with the failures of systems, but seldom attempt to redesign systems to reduce failure" (1998, p.1).

\subsection{Dynamic Complexity}

What makes these systems so complex? And as a result, complicated and difficult to really see what's happening?

As stated previously, we all walk around with mental models of how perceive things to be operating. Yet, generally speaking, these models are grossly insufficient. What makes our mental models so ineffective - like those that likely were the cause in the scenario in Figure 1 - is not their lack of complexity or lack of understanding of the complexity of the system in terms of number of possibilities in making a decision (also known as combinatorial complexity). Rather, it is usually due to dynamic complexity - "the counterintuitive behavior of complex systems that arises from the interactions of the agents over time" (Sterman, 2001, p. 11). The challenging differences between simple and complex systems are many and often direct opposites of one another. For example, in a complex system the actual cause to a behavior may originate from another part of the system, often from a place that is distantly removed; in complex systems, achieving a short-term goal can often mean undesirable long-term consequences; and in complex systems the obvious decision often turns out to be an ineffective one (Forrester, 1997). And of course adding to the complexity of decision- 
making is the very hierarchical nature of complex systems- the goals of a subsystem can contradict or endanger the welfare of the larger system.

An extended discussion of the dynamic complexity of systems is described in Figure 2. It is this type of complexity, and the lack of understanding its nature, that leads to policy resistance and decisions that lead to unintended systemic effects. And it is this complexity that requires to rely on more than our mental models for analyzing complex systems and creating policies and structures that govern the futures of these systems. Doing so has been achieved with considerable success in fields from medicine to environmental change to regional economics using an approach known as system dynamics.

Figure 2. The Dynamic Complexity Characteristics of Complex Systems (adapted from Sterman, 2001, p. 12).

\section{Dynamic Complexity Characteristics of Complex Systems}

- Constantly challenging - Change in systems occurs at many time scales, and these different scales sometimes interact.

- Tightly coupled - The actors in a system interact strongly with one another and with the natural world; everything is connected to everything else.

- Governed by feedback - Our actions feed back on themselves, giving rise to a new situation as a result of our actions.

- Nonlinear - Effect is rarely proportional to cause, and what happens locally in a system often does not apply in distant regions; it arises as multiple factors interact in decisionmaking.

- History-dependent - Taking one road often precludes taking others and determines where you end up; many actions are irreversible.

- Self-organizing - The dynamics of systems arise spontaneously from their internal structure, generating patterns in space and time creating path dependence.

- Adaptive - The capabilities and decision rules of the agents in complex systems change over time. Adaption also occurs as people learn from experience, especially as they learn new ways to achieve their goals in the face of obstacles. Learning is not always beneficial, however.

- Characterized by trade-offs - Time delays in feedback channels mean the long-run response of a system to an intervention is often different from its short-run response. High leverage policies often generate transitory improvement before the problem grows worse.

- Counterintuitive - Cause and effect are distant in time and space while we tend to look for causes near the events we seek to explain.

- Policy resistant - The complexity of the systems in which we are embedded overwhelms our ability to understand them, resulting in many seemingly obvious solutions to problems that fail or actually worsen the problem..

\subsection{System Dynamics}

"The question is not to use or ignore models. The question is only a choice among alternative models" (Jay Forrester, 1971, p. 4)

Understanding the structure and interconnections that create the behavior of a defined system is the goal of system dynamics. System dynamics is a field that helps us to overcome policy resistance and the inherent human limitations described above. The tools of system dynamics demonstrate and unpack the complexity of a system that we might otherwise not recognize; and it counteracts the tendency towards analysis by seeing the system as a whole-which makes the field inherently interdisciplinary.

A system dynamics model is a representation of the structure of a system. Like all models, these models are never fully accurate depictions of the behavior of our world. However, the tools of system dynamics afford us a means of employing the knowledge that underlies our mental models with a more accurate representation of the complexity of the system. Systems are the fundamental structure to our world. Simple systems are nested within larger complex systems, which are nested within in larger complex systems, and so on. Employing system dynamics to construct a useful model requires determining the scope of the system you will examine. Figure 3 diagrams the hierarchical complexity of the U.S. educational system. A system dynamics analysis can be conducted within any of these levels, or between one or more of these levels. Modeling these different dynamics will depend on defining the scope of the problem, which is achieved through the four general tools in system dynamics - described in Figure 4. People are generally most familiar with Behavior-Over-Time Graphs-they help identify a problem or undesirable behavior and therefore a starting place for a system dynamics project. Once the "what" has been defined, Causal Loop Diagrams and Stock/Flow Maps will help identify the "why."

Figure 3. Hierarchical Levels of Educational System Policy Analysis

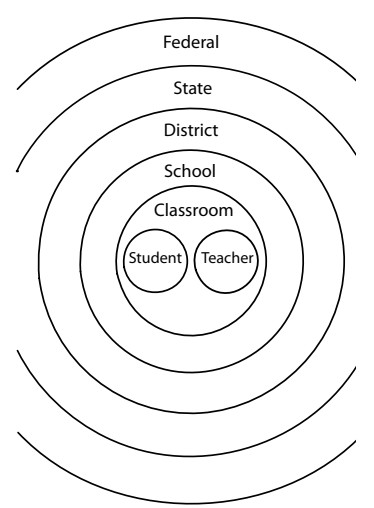

Constructing formal models exposes the assumptions and miscalculations in our mental models. While no model, formal or informal, will ever fully and accurately represent the real world scenario, the usefulness and validity of a constructed model can be based on its ability to clarify our thinking and provide us with insights the system; therefore models can be judged on (Forrester, 1968):

- their clarity of structure, particularly in comparison to the clarity found in the verbal description;

— whether or not the underlying assumptions are more clearly exposed;

— the level of certainty with which they demonstrate the correct time-varying sequences; and

— the ease of communicating their dynamics compared to the verbal description.

Models are tools; therefore a useful and valid model is deemed so when it is determined to be the most useful and valid tool for understanding the situation at hand. By using these tools 
one begins to develop systems thinking, critical to overcoming policy resistance. The next section will expand upon applying system dynamics modeling in education system design; therefore a basic understanding of system dynamics modeling will be necessary. For a brief introduction to the concepts and building blocks of system dynamics models, please stop here and review Appendix - An Example of System Dynamics in Play: A Generic Model of the Spread of Contagious Activity, or Infection.

Figure 4. Tools of System Dynamics (adapted from Catalina Foothills School District, 2003).

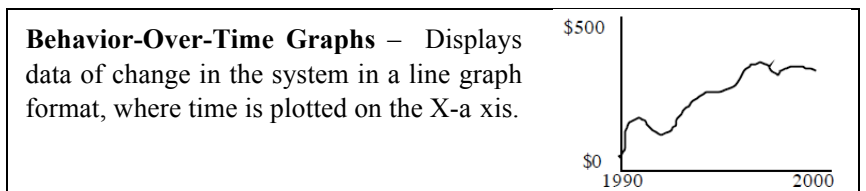

Causal Loop Diagrams - Understanding why the behavior over time is occurring requires understanding the dynamics of the systemwhich generated by causal and feedback loops within the system. Causal Loop Diagrams help us to map loops visually, showing how they may interact with one another.

Stock/Flow Maps - "Stocks" are the accumulation of something in the system, such as money, people, etc. "Flows" are the rates of change of those stocks, such as savings or spending rate.

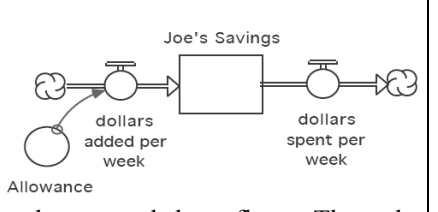
Feedback loops within a system are what control these flows. Through these three components, one can depict the dynamics of a given system. To ols for creating both Causal Loop Diagrams and Stock/Flow Maps include STELLA, Vensim, and DYNAMO.

Computer Simulation

Models - Once a system is

diagrammed, its accuracy

can best be tested through

constructing a computer

simulation of that model.

While no one person

could simultaneously

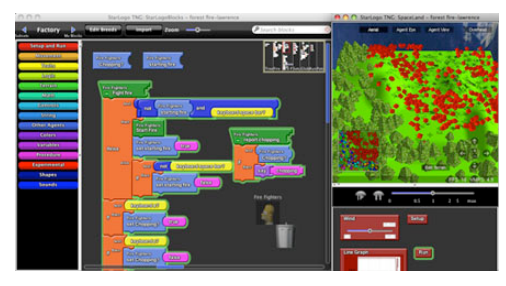

calcu late the interdependent relationships of system of time that produces the troublesome behavior, a computer model can. Numerous tools have been developed to help achieve this, including StarLogo, and NetLogo.

\section{USING DYNAMIC SYSTEMS MODEL IN THE EDUCATIONAL SYSTEM DESIGN}

Given the magnitude and complexity of many national educational systems, system dynamics offers a set of tools and a way of thinking that can not only help us unpack the complexities and drivers of the existing systems, but also offer us the promising hope of strategically crafting future system policies and structures that better enable us to create more effective educational systems. The aforementioned hierarchies found in the U.S. educational system in Figure 4 show the various levels that systems analysis can occur within and between, on numerous variables (stocks). Of course, the most obvious - and the most monitored - system outcome or stock is "student achievement," measured in standardized test scores. However, some experts argue that most of the assessments used for this purpose are not accurately capturing student achievement and cognitive growth in a domain (Dawson \& Stein, 2008); while discussing this is outside the scope of this paper, it is worth highlighting that assessments used to capture the outcomes of a system are human-made, and potentially seriously flawed - which can dramatically affect how the system is perceived and therefore adjustments that are made to the system in a damaging way. Yet even if the assessments developed to measure and track the status of the "student achievement" stock over time, there are countless variables within a system that affect this, and therefore their influence in the system must be explored. Just a few of the possible stocks that could be measured and diagrammed include:

\section{— teacher-student ratio \\ — curriculum scope \\ — teacher attrition \\ — student graduation rates \\ — school accountability ratings}

Some of these stocks, and many more, dramatically impact student achievement and therefore are critical dimensions to a systems analysis of education. Because of the complexity of the hierarchies and the variables within and amongst those hierarchies, it may feel overwhelmingly complex to try to map these dynamics. However, the good news is that any concept that can be clearly described in words can be incorporated into a computer model (Forrester, 1971). The large benefit to mental models is that they represent a vast body of knowledge about the dynamics of the system, which is used to construct more accurate representations and simulations. Likewise, data is a critical piece to constructing good computer simulations and models. One of the greatest strengths of the field of education is the robust and vast array of research and data, which can be used for these purposes. Leveraging these two resources will allow us to construct powerful models of education-affording us the ability to understand the current dynamics and the design stronger policies and interventions going forward.

Below is an example model based on educational research at the national level, modeling dynamics occurring in the U.S. educational system.

\subsection{Classroom Size and No Child Left Behind}

Class size and student-teacher ratio has long been considered a critical factor on student achievement. Although it's tangible impact on student performance has been largely debated, the Center for Public Education conducted a meta-analysis on this literature and have several key findings, including: smaller classes, particularly in grades K-3, can boost student academic achievement; a class size of no more than 18 students per teacher is required to produce the greatest benefits; and minority and low-income students show even greater gains when placed in small classes in the primary grades (Center for Public Education, 2007)

From these findings, we can conclude that class size is a stock that should be monitored. For example, in the mid-1990s, California's average elementary classroom size was 29 students (Bohrnstedt \& Stecher, 2002). By the aforementioned findings, this number is far beyond the scope of an acceptable ratio. The status of this stock could alert us to consider designing and implementing policies that help lower this ratio. In system dynamics language, we might try to understand the current 
dynamics of the system, in order to create new feedback loops that bring this stock down.

We can begin to understand causes of change in a stock such as this by identifying the influences or system elements effecting this change using causal loop diagrams. Often these diagrams are based on the stores of mental models and knowledge we hold. One causal loop we could identify is related to current policy structures of the No Child Left Behind Act (NCLB). This law, enacted in 2001, sought to improve student performance of primary and secondary schools through increasing achievement standards tied to federal funding. Under the law, schools that consistently underperformed were subject to loss of funding and potential takeover by the government. While the policymakers undoubtedly crafted this law with the intent to "push" educators to improve their teaching to provide all students with an adequate education, we can see an unintended reinforcing loop that can ultimately have the directly opposite effect; Figure 5 is a Causal Loop Diagram demonstrating these dynamics. If schools were already struggling with student performance, and these schools had suboptimal student-teacher ratios before NCLB was implemented, they were not positioned well to meet the requirements of NCLB. After continual student underperformance, a school would be subject to diminished federal funding, thereby leaving them with less resources to operate the school. One way this lack of resources is often handled is by consolidating classrooms and increasing the number of students a teacher is given, thereby increasing student-teacher ratio, which we have seen leads to diminished student achievement, and so on, as the loop reinforces itself. Consider also, the third finding listed by the Center for Public Education, showing that minority and low-income students those most targeted by the creation of NCLB - are the ones impacted by student-teacher ratio. Therefore, schools largely consisting of minority and low-income students are the ones most likely to fall into this reinforcing loop.

Figure 5. Causal Loop Diagram of reinforcing loop in the No Child Left Behind Act.

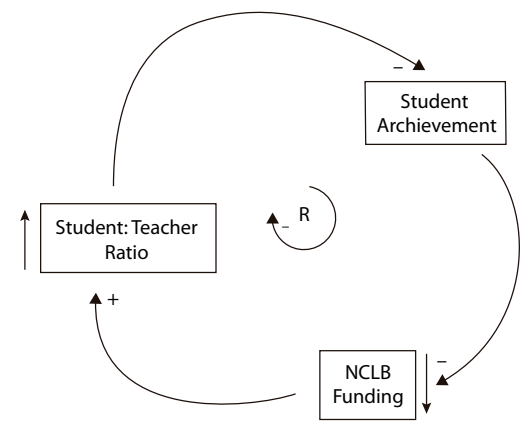

Other dynamics related to this feedback loop can be added to increase the complexity of our model and better understand the true dynamics occurring. For example, at the time NCLB was enforced, many states were in a fiscal crisis, cutting budgets and restructuring (Sunderman, Kim, \& Orfield, 2005); as a result, many schools were not in a position to adequately meet the law's requirements, adding another element that effects the system (see Figure 6). Schools in this situation were ultimately set up to fail from the beginning.

In present form, this model exposes the general dynamics of current structures within the system. This information can, and should, help guide policy construction at the federal level. These models can also be used more locally as well. The next step would be for a more localized school system to expand these models, adding the dynamics that are relevant for their current situation, and then generate a simulation of that model with computer modeling software. Such a process has been demonstrated and leveraged powerfully in numerous other domains to expose the unintended dynamics of system design, and therefore has much to offer the field of education. In the next section, we will demonstrate this process through a case study on Rhode Island and the effects of NCLB on curriculum and instruction in that system.

Figure 6. Causal Loop Diagram of reinforcing loop in the No Child Left Behind Act with reinforcement from state funding dynamics in 2002.

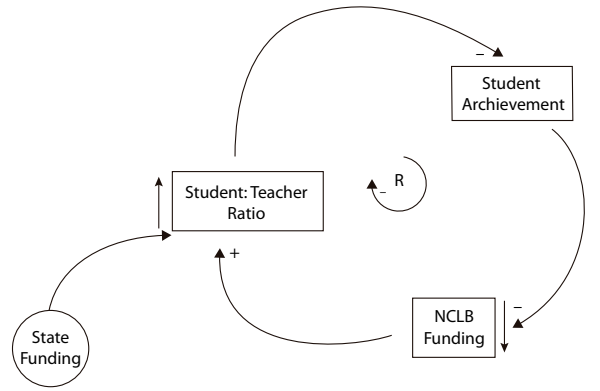

\subsection{Case Study: Rhode Island and the No Child Left Behind Act}

In the 2007-2008 school year, researchers at the Center for Educational Policy (CEP) in Washington, DC, conducted an analysis of the effects of the No Child Left Behind act on curriculum and instruction across K-12 schools in the state of Rhode Island (Srikantaiah, Zhang, \& Swayhoover, 2008). The study included two high schools, one middle school, and three elementary schools, which spanned a mix of schools, both did and did not receive Title I funds for low-achieving students. From an analysis perspective, Rhode Island is a unique situation in that its size allows for more uniformity across the state than would occur in others - allowing data collected to be generalized more easily and applicable to the entire state (as may not be the case for other states in the US). The CEP conducted focus groups and interviewed across the spectrum of stakeholders in these schools - from administrators, to instructional coaches and teachers, to parents and students. As stated previously, this data is not only foundational to the dynamic systems model we hope to generate, but it is these individuals with whom we will seek to analyze our model for consistency and accuracy. In addition to this information, researchers also conducted time-sampling observation of classroom activity as well. Several of their key findings were:

-Use of classroom time for test preparation. Citing pressure to "teach to the test," curriculum was altered to focus on specific content and skills covered by the state standardized test.

-Emphasis on teacher-led instruction. A considerable amount of classroom time was spent asking "closed questions" - similar to what would be found on a multiple-choice test - with less time spent on independent student learning. 
- Increased classroom time spent on tested subject. Study participants reported spending more instructional time on English-language arts and math, which removed class time formerly spent in other areas.

From this data, we can begin to construct our model (see Figure 7). We begin by identifying our stocks; in this case, the curriculum (or subjects) is our stock. Subjects taught and those not taught represent the two stocks that embody this, and therefore the rate of change between them we will call the "content alignment" rate. Now that we have the focus of our model, the goal is to uncover the dynamics that affect this rate. Some of these dynamics are very straightforward. For example, as teachers begin to focus more classroom time on test material, the "Subjects Not Taught/Tested" stock increases, which increases the "class time available." As "class time available" increases, this increases the "exposure to test content," creating a reinforcing loop. "Exposure to test content" is also increased by the decrease in the stock "Subjects Taught/Tested." This variable, "exposure to test content," has two reinforcements and therefore the loop must be completed.

Figure 7. Stock/Flow analysis diagram of dynamic effects of the No Child Left Behind act in the state of Rhode Island in 2008, from the research of the Center for Educational Policy (Srikantaiah, Zhang \& Swayhoover, 2008).

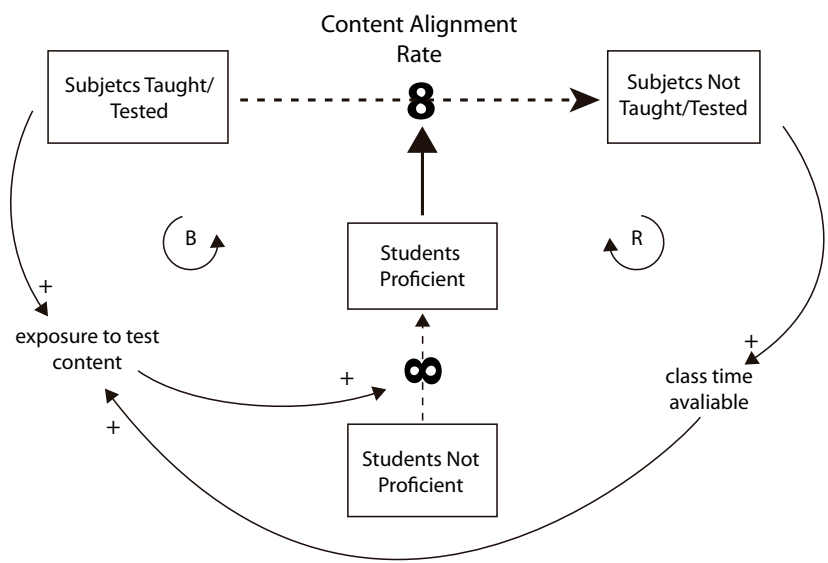

From the data collected by the researchers at the CEP, study participants eluded to the fact that pressure to teach to the test came from the need to meet minimum levels of student proficiency. This identifies the second stock that must be included in our diagram, separated into "Students Proficient" and "Students Not Proficient"-where "proficiency" is a term defined by NCLB in identifying those students who perform at a desirable level on the standardized test. The flow between these two stocks is affected by the variable "exposure to test content" thereby completing the loop and our stock/flow diagram.

\section{DISCUSSION}

The Rhode Island case study presented here offers a very basic application of SD modeling for educational policy in order to demonstrate the SD process and approach. Yet in order to more accurately represent the dynamics of this case study, we must consider adding additional stock(s) - particularly those addressed in this case study such as the pedagogical approach of the teacher (closed questions versus open-ended student inquiry). Next steps would be to engage study participants with our model to elicit their feedback on its validity, and then construct a computer simulation based on actual student achievement data and other data that can be collected such as frequency of various pedagogies and test prep in the classroom.

Even in its current form, we begin to get an understanding of the dynamics at play in the context of this case study. The model suggests that classroom content and behaviors are increasingly aligning to those that are directly related to test preparation. On one level this may be easily dismissed as a given dynamic of having summative tests in education. Yet analyses such as those conducted by the CEP, followed by an SD model can be a powerful way of shining light of unintended - and highly negative - consequences. For example, having the model with supporting data from participants describing the decreased time and attention to any curricular topics other than ELA and Math, as well as data emphasizing the amount of class time that is spent in close-ended question discussion demonstrate two key dynamics that fly in the face of learning theory and research on the design of high quality learning environments (OECD, 2010). Whereas educators and other education stakeholders may have previously only voiced concerns and disagreements about the dynamics and directions of schools and classrooms in light of high-stakes testing, SD modeling offers concrete tools to take to policy makers in identifying detrimental dynamics and advocating for better policy and system designs.

\section{CONCLUSIONS}

How can system dynamics modeling be used more proactively to design educational systems of the future? Avoiding the creation and implementation of policies that have dire effects in the system is of critical importance as the complexity and magnitude of our educational systems continue to expand and, most importantly, the trajectories of our children's learning is altered as a result.

The Organization for Economic Co-operation and Development (OECD) has been leading this consideration with their work on Think Scenarios-which uses scenario modeling to inform educational leadership and policy-making (OECD, 2006). One approach within this work is the "possibility-space" approach - a method for generating a larger set of future scenarios, to get beyond the limitations of "trend-based" scenarios and "preference-based scenarios" (Miller, 2006). In this approach, Miller notes the parallels and tensions in the work done by historians and futurists in scenario modeling (2006). Both use "clues in the present and past in order to substantiate their analyses of why and how life did not or might unfold, using methods and theories that take into account multiple layers of complex interaction and causality" (p. 96). Historian-derived scenarios tend to be limited in vision, locked-in by existing trends-whereas futurist-based scenarios tend to lack accuracy and practicality. As a result, there are two fundamental problems with these approaches: (1) risk of narrowness and lack of imagination, and (2) lack of analytical precision.

System dynamics modeling can bridge these problems. By leveraging this approach and marrying it to the "possibilityspace" approach, educational stakeholders can strategically design future scenarios for education that generate desirable outcomes and are supported by data and models of the past. Very recently, researchers have made significant advances in applying system dynamics and modeling tools to guide future policy development based on analysis of past and current dynamics in education, particularly as it relates to the development of science and math students. Developed by the 
Raytheon company over the past three years, the model process data on variables such as class size, teacher turnover, gender differences, teacher salaries, and data from scholarly research. What is most commendable about this initiative is the support website for the tool, designed to allow anyone who registers to freely download the model and contribute to the analysis and discourse of it - this is where modeling is most powerful, when the tacit knowledge carried by stakeholders within in the system is allowed to rub up against and help form the model, which dramatically increases its validity. Brian Wells, Raytheon's chief systems engineer who helped develop the system, recently explained in an Education Week article that "the model is not meant to provide definitive solutions, but rather help policymakers 'think through the problem, [and] can help you discover unintended consequences" (Cavanagh, 2009). This is a dramatic and noteworthy step in the field of educational policy.

\subsection{Designing the Future}

Moving forward in efforts to change our schools to be effective, sustainable institutions that meet the needs of all learners for the $21^{\text {st }}$ century may feel like a nebulous, daunting task. However, using the lessons we have gained from education reform, education research, and systems work we can build a plan for effectively designing these systems, rather than seeking to make partial changes that have little opportunity to be sustained by the system (Hargreaves, 2003). Transformation means strategically working within the three systems levels (see Figure 3) to redefine the teaching-learning core through disciplined innovation and strategically designing and building an infrastructure to systemically support it.

Of course, this is a tremendous task to say the least. However, the dynamics and effects of the current system demonstrate the critical need for this type of strategic analysis and design. The questions about the future of the educational system to meet the needs of the $21^{\text {st }}$ century, combined with our current state of a tremendous array of educational research, makes this an opportune time for this type of strategic design. Leveraging dynamic systems modeling to meet this goal can help us create an educational system that is effective and fair for all of our students.

\subsection{Using SD to Move the Field Forward}

System Dynamics modeling is a powerful methodology and tool set that has made a dramatic impact in a variety of fields outside education. It represents a transformative leap forward in how we view the world, and in turn respond to it and help design it. One can only speculate as to why such an advancement in approach to dealing with complex society systems has been leveraged so effectively in so many other domains yet remains outside the walls of education, but the answer is regardless of the need to ignore it no longer. Given the state of many schools and educational institutions today, there is not only a clear need for educational to cross this threshold and being leveraging SD but there is also an urgency. At the heart of SD modeling lies systems thinking - a competency or capacity of an individual to see the world as interrelated systems rather than linear and distinct parts (Kauffman, 1980). It's an different frame of mind - one that can and is taught all the time by the numerous educators who see the value of such a mindset. Teaching systems thinking is now commonplace in elite business schools like the MIT Sloan School of Management and even in many elementary schools today (Meadows, 2008). Yet it is far from ubiquitous, and most adults have not had the opportunity to be exposed to experiences and instruction that help them cultivate the capacity of systems thinking.

Advancing our education systems forward requires that we take the first step toward systems thinking, and that we begin to explore this mindset and the principles of complex systems so that we can make more informed decisions and utilize more informed tools like SD modeling. The knowledge is there, with countless examples of how it has worked for other domains, it's up to us to cultivate the will to use it.

\section{REFERENCES}

Axelrod, R. (1976). The structure of decision: The cognitive maps of the political elites. Princeton, NJ: Princeton University Press.

Banathy, B. (1973). Developing a Systems View: The Systems Models Approach. Lear Siegler Fearon Publishers.

Barber, M., \& Fullan, M. (2005, March 2). 'Tri-level development': Putting systems thinking into action. Education Week, 24(25), 32-35.

Berman, P., \& McLaughlin, M. (1978). Rethinking the Federal Role in Education. Santa Monica, Clif: Rand Corporation.

Bohrnstedt, G., \& Stecher, B. (Eds.). (2002). What we have learned about class size reduction. Sacramento, CA: California Department of Education.

Catalina Foothills School District. (2003). Tips for using system dynamics tools. A paper for the Creative Learning Exchange, accessed

www.clexchange.org/ftp/documents/Implementation/IM200312TipsUsingSDTools.pdf on March 2, 2009.

Cavanagh, S. (2009). Computer tool sizes up math, science policies. Education Week, 29(36). Retrieved from www.edweek.org/ew/articles/2009/07/08/36simulate.h28.html.

Center for Public Education. (2007). Research review: Class size and student achievement. Retrieved from http://www.centerforpubliceducation.org/site/c.kjJXJ5MPIwE/b.153 3647/k.3B7C/Class_size_and_student_achievement.htm

Datnow, A. \& Stringfield, S. (2000). Working together for reliable school reform. Journal of Education for Students Placed at Risk, 5(1), 183-204. doi: 10.1080/10824669.2000.9671386

Dawson, T, L. \& Stein, Z. (2008). Cycles of Research and Application in Science Education. Mind, Brain, and Education, 2(2), 90-103. doi: 10.1111/j.1751-228X.2008.00037.x

Forrester, J. (1998). Designing the future. Address at Universidad de Sevilla, Sevilla, Spain. December 15, 1998.

Forrester, J. (1997). System dynamics and K-12 teachers. Lecture given at the University of Virginia School of Education on May 30, 1996. D-4665-4

Forrester, J. (1991). System Dynamics and the Lessons of 35 Years. A chapter written for De Greene, K. (eds.) The Systemic Basis of Policy Making in the 1990s. D-4224-4 Accessed on March 28, 2009 at http://sysdyn.clexchange.org/sdep/papers/D-4224-4.pdf

Forrester, J. (1971). Counterintuitive behavior of social systems. Technology Review, January 1971, 52-68.

Forrester, J. (1969). Urban dynamics. MIT Press: Cambridge, MA.

Forrester, J. (1968). Principles of systems. Waltham, MA: Pegasus Communications.

Fullan, M. (2001). Whole school reform: Problems and promises. Paper commissioned by the Chicago Community Trust. Retrieved from http://www.extranet.ou.nl/inter-studie-alg-

o31411/Symposium4/materiaal/Whole\%20school\%20reform $\% 20$ \%20Fullan.pdf.

Fullan, M. (1999). Change Forces: The Sequel. Philadelphia, PA: Falmer Press, Taylor \& Francis Inc.

Fullan, M. (1995). The school as a learning organization: Distant dreams. Theory into Practice, 34(4), 230-235. doi: 10.1080/00405849509543685

Fullan, M. (1994). Coordinating top-down and bottom-up strategies for educational reform. In R. Anson (Ed.) Systemic Reform: Perspectives on Personalizing Education, 7-24.

Fullan, M. (1991). The new meaning of educational change. New York, NY: Teachers College Press.

Fullan, M., Rolheiser, C., Mascall, B., \& Edge, K. (2001). Accomplishing large scale reform: A tri-level proposition. Prepared 
for the Journal of Educational Change. Retrieved from http://www.michaelfullan.ca/Articles_01/11_01.pdf.

Garet, M. (1974). Educational policy and system dynamics. Journal of Research and Development in Education, 7(2), 119-144.

Groff, J. (2009). Transforming the Systems of Public Education. Nellie Mae Education Foundation.

Hargreaves, D. (2003). Education epidemic: Transforming secondary schools through innovation networks. A DEMOS whitepaper.

Jennings, J., \& Rentner, D. (2006). Ten big effects of the No Child Left Behind Act on public schools. A report from the Center on Education Policy. Retrieved from http://www.cep-dc.org

Kauffman, D. (1980). Systems one: An introduction to systems thinking. Minneapolis, MN: Carlton.

Krone, E. (2008). Boycotting NCLB: In effort to protect students Illinois district will refuse test. The Daily Herald (Illinois) on February 22, 2008.

McMurrer, J. (2008). Instructional time in elementary schools: A closer look at changes for specific subjects. A report from the Center on Education Policy. Retrieved from http://www.cep-dc.org

Meadows, D. (2008). Thinking in Systems: A Primer. The Sustainability Institute.

Meadows, D. (1991). The global citizen. Washington, DC: Island Press.

Miller, R. (2006). Future studies, scenarios, and the "possibility-space" approach. In OECD, Think scenarios, rethink education. 93-105. doi: 10.1787/9789264023642-7-en

OECD (2010). The Nature of Learning: Using Research to Inspire Practice. Organisation for Economic Co-operation and Development - Centre for Educational Research and Innovation. Paris, France.

OECD (2006). Think Scenarios, Rethink Education. Organisation for Economic Co-operation and Development - Centre for Educational Research and Innovation. Paris, France.

Pascopella, A. (2004). Inside the law: Analyzing, debating and explaining No Child Left Behind. District Administration, April 2004.

Quaden, R., Ticotsky, A., \& Lyneis, D. (2009). The infection game. The Creative Learning Exchange, 18(1), p. 1-12

Srikantaiah, D., Zhang, Y., \& Swayhoover, L. (2008). Lessons from the Classroom: Federal and State Accountability in Rhode Island. A Center for Educational Policy Report. Washington, DC.

Sterman, J. (2001). System dynamics modeling: Tools for learning in a complex world. California Management Review, 43(4), 8-25. doi: $10.2307 / 41166098$

Sunderman, G., Kim, J., \& Orfield, G. (2005). NCLB Meets School Realities: Lessons From the Field. Corwin Press.

Wheat, D. (2000). A systems approach to education policy and administration. Presented at the Systems Thinking and Dynamic Modeling Conference in Portland, Oregon, June 25, 2000. Retrieved from

www.clexchange.org/ftp/conference/cle_2000/session\%2044.pdf.

\section{ACKNOWLEDGMENT}

Supporting Agencies: Nellie Mae Education Foundation; Harvard University 


\section{APPENDIX}

\section{An Example of System Dynamics in Play: A Generic Model of the Spread of Contagious Activity, or Infection}

Contagious activity - that of a virus, computer virus, rumor, fad, social movement, etc.-follows the same basic structure. The behavior-over-time graph represents the general number of affected people over time.

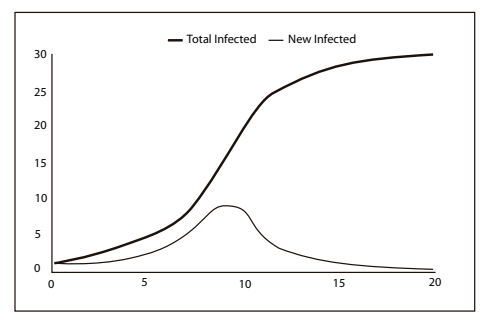

Example of a behavior-over-time.
The graph demonstrates a characteristic s-shaped curve of infections over time, with the number of new infections increasing then declining, cause a depression in the rate of overall infection. What is the underlying system dynamics causing this behavior? Other system dynamics tools can help us model this system behavior.

Causal Loop Diagrams Since a system is composed of a collection of items that interact with one another, the parts of the system have a circular relationship, or a "loop"-where output, or behavior, of a system is fed back into the system itself to affect future behavior. Therefore, the central building block for Causal Loop Diagrams are correctly diagramming the feedback loops within a system. The type of feedback loop is determined by the effect it has in the system, which includes:

-Negative/Balancing - system elements seek to "negate" any changes in the system, thereby pursuing balance and stabilization in the system; this is the most common type of feedback loop.

- Positive/Reinforcing - these are the drivers of growth within a system and amplify change.

Example of a causal loop diagram.

We can see both loops at work in infectious behavior. As the number of people infected increases, the exposure rate is greater

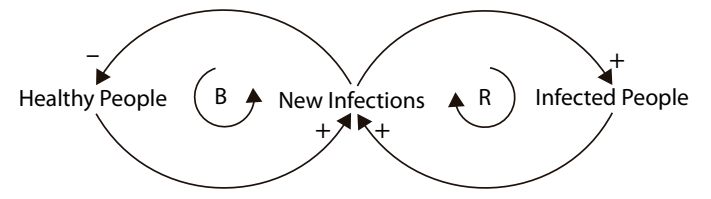

thereby increasing the amount of new infections. Since the number of healthy people is declining, the actual number of new infections will lessen over time.

Stock/Flow Maps Causal loop diagrams can begin to uncover what is happening in a system, but they are only a rough sketch. Stock/flow maps can more accurately unpack the dynamics of the system by outlining the movement of items in the systems and the forces causing that moving. The central components to a stock/flow map include:

- Stock - an accumulation of something in the system, either concrete (people, dollars) or abstract (anger); the "nouns" of the system. Stocks can only be affected by flows.

- Flow - action or force that moves things in a system (the "verbs"); this is always a rate, defined in terms of unit of stock over time

- Converter - policy or information that affects the rate of flows in a system.

- Connector - carries information from one part of the system to another.

Generating a stock/flow map, or a simulation, consists of:

1) Identifying the critical stock(s), based on the desired unit of analysis (such as that which is illustrated in a behavior-over-time graph)

2) Determining what flows are affecting the changes in these stocks

3) Defining the elements in the system that influence the rates of the flows (converters/connectors)

4) Identifying feedback from the stocks that makes the system dynamic

For the dynamics of infection, constructing a stock/flow map might look something like this:

In an infection epidemic, people are the stock, but this must be noted in two separate stocks - healthy people and infected people:

\begin{tabular}{l|} 
Healthy \\
People
\end{tabular}

Infected People

Therefore, the flow affecting the quantities of these two stocks would look like this:

\begin{tabular}{|c|c|c|}
$\begin{array}{c}\text { Healthy } \\
\text { People }\end{array}$ & Getting Sick & $\begin{array}{c}\text { Infected } \\
\text { People }\end{array}$ \\
\cline { 2 - 3 }
\end{tabular}

As this flow has time to work, people from the "healthy" stock will be moving over to the "infected" stock. How does this action affect the rate or flow of people getting sick? As the number of people infected increases, so does the chance that a healthy person will be exposed to the sickness, thereby producing a reinforcing loop on the "getting sick" rate.

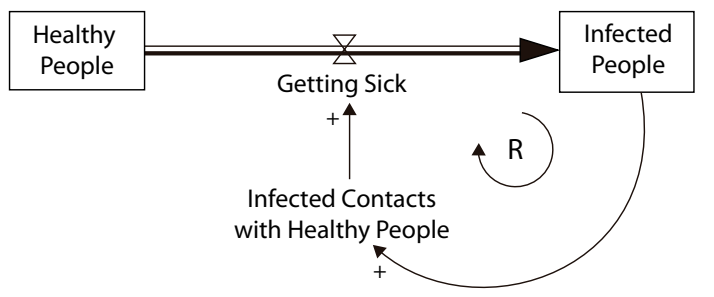

But how does the "healthy" population interaction with the "Infected Contacts with Healthy People" variable? The number of "Infected Contacts with Healthy People" depends on the proportion, or fraction, of the population that was still healthy. When a larger fraction of the population was healthy, the chance of an infected person meeting a healthy person was higher. The "Fraction That Is Healthy" is the fraction of the whole class that is still healthy. It represents the likelihood that an infected person will meet a healthy person.

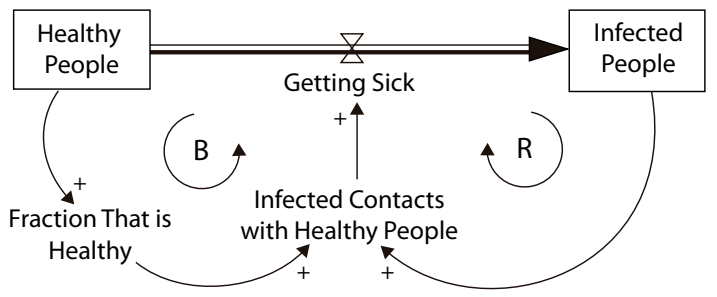

*Adapted from Quaden, R., Ticotsky, A., \& Lyneis, D. (2009). The infection game. The Creative Learning Exchange, 18(1), p. 1-12. 